\title{
AS ORIGENS DO ENSINO DE HISTÓRIA NO BRASIL COLONIAL: APRESENTAÇÃO DO EPÍTOME CRONOLÓGICO, GENEALÓGICO E HISTÓRICO DO PADRE JESUÍTA ANTÓNIO MARIA BONUCCI1
}

\author{
Flávio Massami Martins Ruckstadter \\ Universidade Estadual de Maringá (UEM) \\ ruckstadter@bol.com.br \\ Vanessa Campos Mariano Ruckstadter \\ Universidade Estadual de Maringá (UEM) \\ vanessaruck@bol.com.br
}

\begin{abstract}
RESUMO:
Este texto tem o intuito de apresentar o primeiro compêndio escolar de História utilizado no Brasil. Escrito pelo padre jesuíta, e professor do Colégio Jesuítico da Bahia, António Maria Bonucci (1651-1728) em fins do século XVII, o Epítome Cronológico, Genealógico e Histórico foi impresso no ano de 1706 em Lisboa. Sua publicação vinha atender uma necessidade advinda da implantação de cursos autônomos de História nos Colégios da Companhia de Jesus no Brasil. A junção da história sacra e profana é uma característica presente nesse manual, que se ocupa principalmente em contar a história sacra, a história da Igreja e a história das monarquias modernas. Ao apresentar o compêndio, algumas considerações e comentários serão feitos, entretanto, sem a pretensão de analisar um livro tão extenso em tão curto espaço. Espera-se contribuir no sentido de ampliar e diversificar as fontes para o estudo de um período que ainda recebe pouca atenção por parte dos historiadores da educação, o período colonial, especialmente o que corresponde ao período da atuação da Companhia de Jesus (1549-1759).

Palavras-Chave: História da Educação no Brasil, Século XVIII, António Maria Bonucci, Epítome Cronológico, Genealógico e Histórico.
\end{abstract}

\section{THE BEGGINING OF HISTORY TEACHING IN COLONIAL BRAZIL: PRESENTATION OF THE EPÍTOME CRONOLÓGICO, GENEALÓGICO E HISTÓRICO OF THE JESUIT FATHER ANTÓNIO MARIA BONUCCI}

\begin{abstract}
:
This text has the purpose of presenting the first text-book of History used in Brazil. Written by the Jesuit father and professor of Bahia's Jesuit School, António Maria Bonucci (16511728 ) in the ends of the $17^{\text {th }}$ century, the Epitome Cronológico, Genealógico e Histórico was printed in 1706 in Lisboa. Its publication attended a necessity proceeding from the implantation of autonomous classes of History in the Schools of the Society of Jesus in Brazil. The connection of sacred and profane history is a distinguishing mark of this school book, which tells the sacred history, the history of the Catholic Church and the history of the modern monarchies. When presenting the compendium, some considerations and comments will be done, however, without the pretension of analyzing such an extensive book in so small space. It is expected to contribute with the increase and the diversification of the sources to the study of a period that still receives insufficiently attention by the education historians, the colonial period, specially the one that corresponds to the period of the Society of Jesus actuation (1549-1759).

Keywords: History of Education in Brazil, $18^{\text {th }}$ century, António Maria Bonucci, Epítome Cronológico, Genealógico e Histórico
\end{abstract}




\section{Introdução}

A proposta deste texto consiste na apresentação do Epítome Cronológico, Genealógico e Histórico publicado no ano de 1706 e escrito no Brasil pelo padre missionário jesuíta António Maria Bonucci (1651-1728). Trata-se do primeiro manual de História escrito no Brasil e com a finalidade de ser utilizado no Colégio Jesuítico da Bahia, em fins do século XVII. Para tanto, iremos inserir nosso ator principal e sua obra no momento no qual viveu e produziu esse manual, bem como considerar o período de atuação mais ampla da Companhia de Jesus no Brasil (1549-1759). O presente trabalho parte de um recorte definido momentaneamente; por esse motivo, antes de apresentar o epítome, será feita uma breve incursão pelo contexto brasileiro e europeu nos séculos XVI a XVIII, para melhor compreensão do período e do compêndio.

É preciso salientar que o manual escrito por Bonucci não pode ser identificado, em virtude do momento em que foi escrito, com um manual que traga uma perspectiva de história científica. A História, enquanto ciência, nasceria somente durante o século XIX. Ainda assim, é uma importante fonte documental sobre o período de atuação jesuítica na colonização do Brasil.

Primeiro serão apresentadas informações biográficas e autorais do padre Bonucci. Na sequência, o contexto no qual Bonucci viveu e atuou, partindo de uma breve discussão sobre a colonização brasileira e a atuação dos padres jesuítas na catequese dos silvícolas. Será ainda considerado o final do século XVII e suas peculiaridades em relação aos primeiros anos de atuação dos padres jesuítas. Por fim, será realizada uma apresentação comentada do manual.

O intuito não é o de realizar uma análise do texto e do ensino de cursos autônomos de História nos colégios jesuíticos que adotaram esse manual, mas sim, possibilitar a ampliação e diversificação de fontes primárias para o estudo do período jesuítico, pouco discutido na historiografia da educação, porém importante para a compreensão da origem da formação da cultura no Brasil, e, por consequência, da educação brasileira.

Estudos recentes têm demonstrado a reduzida preocupação, por parte dos historiadores da educação, em discutir temas referentes à atuação jesuítica no Brasil entre os séculos XVI e XVIII. Bittar e Ferreira Júnior (2007), por exemplo, afirmam que existe uma lacuna na produção sobre o tema em apresentações em congressos, artigos científicos e também nas pesquisas em programas de pós-graduação, mas vislumbram boas possibilidades para aqueles que aderem à temática. Primeiro porque ainda há muito a se fazer, dado o reduzido número de trabalhos; segundo, em consequiência, porque as chances de contribuir com produções inéditas são muito maiores do que se estivessem se dedicando a temas mais recorrentes na historiografia. É nesse sentido que este texto procura contribuir.

\section{Vida e obra de António Maria Bonucci}

Poucas são as informações disponíveis sobre a biografia do padre António Maria Bonucci (cuja grafia também pode ser encontrada como Anton-Maria Bonucci). A escassez pode ser constatada em um levantamento de fontes na historiografia e também no Banco de Teses da Coordenação de Aperfeiçoamento de Pessoal de Nível Superior (CAPES). Dentre 
as poucas informações encontradas, nesta discussão serão utilizadas como referências aquelas que estão dispersas na obra do padre Serafim Leite, História da Companhia de Jesus no Brasil, especialmente nos Tomos VI e VII, que tratam da fundação dos colégios jesuíticos em todo o domínio português e do estabelecimento da Companhia de Jesus em terras brasileiras, respectivamente.2 Outra fonte que fornece alguma informação sobre o padre António Maria Bonucci é o Diccionario Histórico de la Compañia de Jesús, um dicionário biográfico-temático, no qual o verbete sobre o padre jesuíta se resume a uma coluna de uma página. Essas são as duas mais significativas fontes para iniciar esta discussão.

Professor de Humanidades do Colégio da Bahia3, o missionário italiano Bonucci foi também secretário do padre Antonio Vieira (1608-1697), e ficou responsável pela compilação e publicação das cartas e sermões de Vieira após a morte do provincial da Companhia de Jesus no Brasil (SERAFIM LEITE, 2000, p. 90). Antes de escrever o Epítome, publicou em Roma, no ano de 1703, o livro Manuductio ad Rhetoricen e' Severiori Veterum Oratorum Discipina, et praesertim e' sacris utriusque linguae Patribus qui mascula Eloquentia floruerunt, breviter deprompta, um "Manual de Padres de uma e outra língua, isto é, gregos e latinos" (SERAFIM LEITE, 2000, p. 162).4

Há também informações sobre Bonucci em uma carta do padre Antônio Vieira, a Clavis Prophetanum. Nessa carta, Vieira, de quem Bonucci foi secretário e responsável pelo inventário das primeiras centúrias das suas cartas, descreve Bonucci e seu trabalho:

\begin{abstract}
Nas elucubrações, em que de há muitos anos a esta parte afincadamente medito acerca da Consumação do Reino de Cristo na Terra, trabalha juntamente comigo, empenhadamente, o Padre António Maria Bonucci, o único que eu escolhi, com vénia do Padre Provincial, como capacíssimo de suportar um trabalho ingrato, pessoa de índole muito dócil em quem as qualidades de engenho, discernimento e de estilo concorrem com o requinte da erudição, de tal sorte que considero como suprema felicidade tê-lo chamado a concluir esta obra. Apoiado no zelo deste homem e no seu empenho espero, sob o auspício da divina Majestade, no próximo ano dar a última demão a esta dissertação, há tanto tempo iniciada, e colocarlhe um ponto final (VIEIRA, 2007)
\end{abstract}

Por ocasião de sua atuação como professor no colégio da Bahia, Bonucci escreveu um manual para utilizar em suas aulas, prática comum entre os padres jesuítas. Para falar da atuação de Bonucci, antes é necessário falar da atuação dos padres jesuítas, especialmente na educação. Foram eles os responsáveis pela sistematização da educação no Brasil. Por essa razão, não é possível compor uma análise da história brasileira entre os séculos XVI e XVIII sem considerar o decisivo papel desempenhado pela Companhia de Jesus, tanto no projeto colonizador português, de modo mais geral, ou ainda na atuação efetiva na catequese dos índios, na fundação de missões, de casas de primeiras letras e colégios, ministrando os sacramentos ou ainda como homens de negócios.

A presença dos padres da Companhia de Jesus no Brasil era estendida, além da religião e educação, também à administração pública e à economia (ASSUNÇÃ̃, 2004; FREYRE, 1981; BUARQUE DE HOLLANDA, 2002; MORAES, 2000). Os jesuítas compunham o projeto civilizador português que determinou a formação da cultura brasileira (FELIPE DE ALENCASTRO, 1998).

A descoberta e consequente conquista do Brasil se deram em meio a um espírito reformista, o que fez da Companhia de Jesus, devido a seu fervor missionário, a arma apropriada para a expansão da fé católica nessas novas terras. Além de propagar a fé 
católica, os jesuítas foram os primeiros a instituir um ensino letrado e sistematizado nos domínios portugueses no Novo Mundo. Esse momento de nossa História da Educação foi periodizado por Saviani (2008) como pedagogia brasílica (1549-1599), da chegada dos jesuítas até a publicação do Ratio Studiorum, iniciando um novo período que se estende até a expulsão dos jesuítas do Brasil no ano de 1759, que o autor chama de pedagogia jesuítica.

O período em que os jesuítas estiveram no Brasil (1549-1759), teve grande importância, não somente por seu projeto missionário, mas também por sua empreitada educacional. A educação jesuítica no Brasil deve ser entendida dentro de um projeto maior: o da colonização do Brasil. Também há que se considerar o caráter predominante dessa educação, especialmente nos primeiros anos: a catequese do gentio.5

Entretanto, superados os chamados tempos heróicos, os jesuítas se ocuparam na instrução dos filhos dos colonos e na formação de padres para compor os quadros da própria Companhia. O manual que aqui será apresentado foi utilizado no século XVII, apesar de somente publicado no século XVIII, no colégio da Bahia e não tinha por finalidade a catequese, mas sim o ensino da história sacra e profana no curso de Humanidades oferecido nesse colégio.

Quando a Companhia de Jesus foi fundada, no século XVI, não havia em nenhum colégio ou universidade do mundo o ensino de História como disciplina autônoma. Foi nos colégios jesuíticos que a disciplina de História passou a ser ensinada pela primeira vez. A história era, nesse período, importante instrumento de interpretação utilizado nos cursos de Humanidades, principalmente as histórias da Grécia e de Roma Antigas, bem como nos cursos de Teologia, onde era ensinada como complemento à História da Igreja. Foi somente no século XVIII que surgiram os primeiros cursos de História, que consistiam em História Pátria e logo História Geral. Posteriormente, apareceram os primeiros manuais, com a finalidade de serem utilizados nesses cursos. Nas escolas da Companhia de Jesus, o primeiro livro adotado foi o Epítome de Turssellini, substituindo o livro do português Orósio, que datava do século $\mathrm{V}$, até então utilizado nos cursos de Humanidades. Já o manual escrito por António Maria Bonucci no século XVII, substituiu por sua vez o Epítome de Tursselini nas escolas da Companhia no Brasil.

Bonucci participou do processo de canonização de D. Afonso Henriques, testemunhando sobre o episódio conhecido como Milagre de Ourique. O governo de D. João V procurou reforçar o pedido de canonização de D. Afonso Henriques com uma vasta operação de propaganda junto à cúria romana, tendo se empenhado numa campanha de publicação, em Itália, da vida prodigiosa do rei português, razão pela qual hoje se guardam na Biblioteca do Vaticano vários manuscritos e impressos redigidos por estrangeiros contendo alusões ao Milagre de Ourique. Um dos mais importantes é o livro de Bonucci, dado ao prelo em Veneza no ano de 1719, onde se narra a miraculosa cura do jovem príncipe obtida perante uma imagem da Virgem, além de fundamentar os motivos que constrangeram o santo rei a declarar guerra à mãe para defender a herança paterna. Bonnuci prossegue dando grande relevo ao zelo religioso de D. Afonso Henriques, para depois descrever com extrema minúcia a já bem conhecida promessa feita por Cristo ao primeiro soberano português. O mais interessante, porém, e que denuncia o interesse político da Coroa Portuguesa na publicação deste gênero de relatos, é a forma como o autor se serve das profecias do Salvador para elogiar todos os monarcas brigantinos, com exceção de D. Afonso VI, apenas discretamente mencionado. Fica evidenciada aqui a tradição do período em escrever vidas de santos, marca na literatura produzida por Bonucci. 


\section{Apresentação comentada do manual}

A primeira edição que aqui será apresentada se encontra na Biblioteca Nacional de Lisboa, que conta com sete exemplares disponíveis para consulta. Seis deles estão na coleção do Fundo Geral de Monografias e um na coleção de Impressos reservados. Foram identificados dois lugares no Brasil nos quais há a obra. O primeiro é a Biblioteca da Câmara dos Deputados. O segundo é a biblioteca Instituto de Estudos Brasileiros (IEB) da Universidade de São Paulo (USP). 6

A obra é dividida em quatro livros que totalizam 555 páginas, e une História Sacra e Profana. Na apresentação ao leitor, Bonucci enfatiza que a motivação para escrever esse manual foi utilizá-lo em suas aulas, mas que depois de dez anos resolveu publicá-lo, pois o epítome poderia:

(...) servir por huã parte de forte argumento, que mostre aos incrédulos a realidade da vinda do Divino Messias; \& (...) de forma de solida consolação aos Catholicos, que reconhecem, adorão, \& amão a Christo, como a seu Deos, \& Senhor (BONUCCI, 1706)

Entretanto, é preciso salientar que no século XVIII, a História, ainda que não se constituísse como ciência autônoma, foi utilizada nos colégios jesuíticos europeus com a finalidade de legitimar a formação dos Estados Nacionais, especialmente no que diz respeito ao sentimento nacional. A formação de um sentimento nacional no Brasil em fins do século XVII correspondia, entretanto, a reforçar o sentimento de pertencimento à Portugal, sobretudo aos filhos dos colonos e aos futuros membros da Ordem, uma vez que, pelo regime do Padroado, os padres jesuítas que aqui estavam em missão eram também funcionários da Coroa Portuguesa. Dessa forma, Bonucci une em seu compêndio a História Sacra, com ênfase à história dos profetas bíblicos, especialmente Jesus, e da Igreja Católica, e a História profana, dos reinos da antiguidade até os reinos da modernidade. As histórias das monarquias são, em geral, apresentadas a partir da cronologia dos reis, para legitimar a construção das nações. Uma história que se apresenta em uma perspectiva cristã-eurocêntrica. Quando há a menção no manual a reinos do Oriente, a finalidade é legitimar a construção do cristianismo, mas, sobretudo, da Igreja Católica - dado o contexto da cisão da unidade cristã-ocidental - e a grandeza dos Estados Nacionais Modernos Europeus, respectivamente.

Logo após a apresentação ao leitor, encontram-se as licenças para a publicação da obra. As autorizações, datadas de 1703, possibilitaram que o livro fosse impresso em 1706 na Officina de Antonio Pedrozo Galram, na cidade de Lisboa. Além da permissão da Companhia de Jesus, Bonucci submeteu seus escritos ao Tribunal do Santo Ofício. Instrumento jurídico utilizado durante a Idade Média pela Igreja Católica, o Tribunal do Santo Ofício, ou da Santa Inquisição, foi amplamente utilizado na Modernidade no movimento que se convencionou chamar de Contra-Reforma Católica. Juntamente com a Companhia de Jesus, foi um instrumento utilizado para deter o avanço protestante e propagar a fé católica.

Na ocasião, a autoridade maior da Companhia na Província de Portugal era o padre provincial Miguel Dias, que assinou a licença para que o livro fosse impresso. Outras quatro licenças se seguem a esta, sendo todas de membros do Santo Ofício. No caso da inquisição, o livro foi liberado por não haver "cousa alguã contra nossa santa Fé" (BONUCCI, 1706). 
Além das licenças da Companhia e do Tribunal, entretanto, era necessária a aprovação da Coroa Portuguesa, uma vez que a Igreja Católica e o Estado português eram unidos pelo regime do Padroado,

[...] um instrumento jurídico tipicamente medieval que possibilitava um domínio direto da Coroa nos negócios religiosos, especialmente nos aspectos administrativos, jurídicos e financeiros. Porém, os aspectos religiosos também eram afetados por tal domínio. Padres, religiosos e bispos eram também funcionários da Coroa portuguesa no Brasil colonial. Isto implica, em grande parte, o fato de que religião e religiosidade eram também assuntos de Estado (e vice-versa em muitos casos) (ARNAUT DE TOLEDO; RUCKSTADTER, RUCKSTADTER, 2006).

Isso explica a necessidade da autorização régia para a publicação do epítome. Também na fundação de colégios da Companhia essa autorização era necessária.

O primeiro livro é composto de vinte e dois capítulos. Bonucci inicia seu epítome com a origem do mundo, que tem por base o criacionismo bíblico, que apresenta um Deus que criou o mundo em seis dias e descansou no sétimo. Utiliza como fonte exclusivamente o primeiro capítulo do livro de Gênesis, citado pelo autor já no primeiro parágrafo do capítulo.

Na sequência, apresenta uma periodização da história do mundo, também baseada na história bíblica. As seis idades do mundo vão de Adão até a segunda vinda de Jesus Cristo. $\mathrm{O}$ autor estabelece a mesma genealogia apresentada na história cristã como parâmetro para tal divisão. Menciona uma sétima idade, que não seria nesse mundo, mas sim no céu.

Das seis idades definidas, a que se difere das outras por mesclar a história sacra com a profana é a quarta, que teria início no:

(...) quinto anno do Reynado de Salamão (sic), ou do segundo anno depois de ter começado o Templo; \&durou atè que se destruio, \& queymou o mesmo Templo, ou atè o fim do cativeyro de Babylonia, quatrocentos\&concoenta\&dous annos (BONUCCI, 1706, p. 03).

Nesse período acima estabelecido, o autor intercala a ação dos profetas bíblicos com a história das origens das civilizações greco-romana, dos assírios e dos medos (persas). Justifica a importância do ensino da história desses povos "pois frequentemente se usão na dita Escritura" (BONUCCI, 1706, p. 42).

O livro II do Epítome Chronológico, Genealógico e Histórico contém, nas palavras do próprio autor:

[...] breve noticia dos Summos Pontífices, Concilio, Santos Padres, Doutores, e outros successos mais notáveis que acontecerão no Estado da Igreja, desde a morte de nosso Senhor Jesus Christo até nossos tempos (BONUCCI, 1706, p. 141)

Esse livro é dividido em nove capítulos. Destes, destaca-se o sexto, intitulado Das grandes, e ilustres pessoas em santidade e doutrina, pela fé, e contra os hereges, e na História. Nele Bonucci realiza todo um discurso de exaltação a figuras consideradas importantes, divididas por século, prática comum àqueles que se dedicaram às obras de 
cunho histórico no interior da Igreja durante os tempos medievais e mesmo durante a Modernidade.7 Destaca-se ainda o capítulo IX, Dos successos mais dignos de memoria, que houve em todos os séculos da Igreja; os quaes são evidentissimos argumentos da verdade de nossa Santa Fé Catholica, e da assistencia, e patrocinio de Deus sobre ela. Enquanto o capítulo VI destaca a ação dos homens importantes e santos de acordo com os dogmas da Igreja, esse capítulo exalta a história da própria instituição católica e seus feitos, chamados de sucessos mais dignos de memória:

De tudo que está dito atè agora, quem não vê e quase toca as mãos as excellencias da Religião Christã, e a verdade da doutrina, que a Fé nos ensina? Neste breve Compendio claramente conhecemos, que nenhuma maneira de religião se tem visto até agora mo mundo, onde houvesse TAM grande numero de bons, e Santos, como nesta dos Christãos (BONUCCI, 1706, p. 265-266).

Após a cisão da unidade cristã ocidental no século XVI, a Igreja Católica, que vinha perdendo prestígio desde fins da Idade Média, viveu momentos de instabilidade institucional. Todavia, o movimento conhecido como Contra-Reforma não se limitou a uma simples reação a reforma iniciada por Lutero. As circunstâncias eram caóticas para o Catolicismo. O próprio papa Paulo III reconheceu a necessidade de enfrentar o triplo perigo ao qual estava exposta a Igreja: o avanço dos turcos, o esfacelamento político e a desagregação religiosa (DANIEL-ROPS, 1999, p. 81). Percebe-se, assim, o esforço do jesuíta em enfatizar os grandes feitos da Igreja enquanto instituição, não somente da história sacra apresentada pela bíblia. Seu manual não apresenta somente um resumo da bíblia, mas sim, no que se refere ao livro II, o esforço por (re) construir uma imagem grandiloquente da própria Igreja Católica.

O livro III se divide em onze capítulos e trata da Igreja do Oriente. Primeiro, narra a história dos patriarcas de Constantinopla, Alexandria, Antioquia e Jerusalém (capítulos I ao IV). Em seguida o autor apresenta os "successos mais memoraveis, que acontecerão na Igreja do Oriente" (capítulo V). Posteriormente, trata dos hereges e dos sinais de heresia apontadas pelos Santos Padres (capítulos VI a X). Por fim, apresenta o número e série das perseguições contra a igreja (capítulo IX). Interessante observar o espaço dedicado por Bonucci à questão da heresia no livro III: de onze capítulos, cinco tratam do tema através dos séculos; inicia com aquele que o autor considera o primeiro de todos os hereges: Judas Iscariotes. Tal preocupação parece se justificar quando se lembra que o epítome foi utilizado em fins do século XVII em um colégio jesuítico no Brasil. Nesse sentido, fazia parte dos esforços da Ordem e da Igreja Romana manter sua hegemonia entre colonos e colonizados. Em um primeiro momento a atuação dos inacianos objetivava a catequese dos índios e foi determinante no processo de aculturação. Mas superada a fase inicial, as ações dos jesuítas visavam manter os colonos submetidos aos dogmas da Igreja e às imposições da metrópole.

O livro IV é, sem dúvida, aquele que mais mescla aspectos da história religiosa e da história profana. Dividido em treze capítulos, nesse livro Bonucci apresenta imperadores do Oriente e Ocidente desde a morte de Jesus Cristo e também os reis das nações modernas, tais como Portugal, Espanha, França, Grã-Bretanha, Suécia, Escócia, Hungria e Polônia. Os monarcas são tratados como heróis, nas palavras do autor já na introdução:

[...] Agora neste quarto livro te mostrarey honrada ainda das mais soberbas cabeças dos Principes da terra, corteja das majestades dos monarcas mais soberanos, e reconhecida por mestra da sobrehumana 
sabedoria das grandes, e nobilissimas almas dos Heroes [...] (BONUCCI, 1706, p. 417)

Vale observar que no capítulo VI, dedicado aos reis de Portugal, Bonucci exalta de maneira especial os monarcas lusitanos, uma vez que era essencial à obra da Companhia de Jesus o seu bom relacionamento com a Coroa.

\section{Conclusão}

Nos Tempos Modernos a Igreja Católica enfrentou uma crise enquanto instituição. $\mathrm{O}$ poder político, econômico e religioso foi paulatinamente enfraquecido na medida em que uma nova relação econômica surgia, e com ela uma nova sociedade. Desde fins do século XII a Igreja vinha se reformando, mas foi com a cisão da unidade cristã no ocidente após a Reforma Protestante no século XVI e a instabilidade gerada pelas disputas religiosas, políticas e econômicas com os mouros que se iniciou o movimento denominado Contra-Reforma. Nesse contexto a Companhia de Jesus se tornou uma importante arma da Igreja e do Estado português, tanto na conquista de novas terras quanto de novos fiéis, sobretudo por meio de sua empreitada educacional.

Nos primeiros anos após a chegada dos padres no Brasil o objetivo central era o da catequese do gentio (pedagogia brasílica). Entretanto, com a superação dos tempos heróicos, houve a atuação dos jesuítas no ensino dos filhos dos colonos nos colégios da Companhia no Brasil.

Principalmente após a publicação das normas maiores dos colégios, o Ratio Studiorum, em 1599, houve a regulamentação do que deveria ser ensinado nos colégios da Ordem em todo o mundo. Quando se fala da atuação do jesuíta António Maria Bonucci é nessa perspectiva de ensino, não mais somente da catequese.

Como professor de Humanidades, Bonucci escreveu um compêndio para utilizar como material no ensino de História no colégio da Bahia. A história como uma ciência autônoma nasceu somente no século XIX. Assim, o Epítome Cronológico, Genealógico e Histórico aqui apresentado não é um exemplo deste tipo de história que se concretizaria como científica um século mais tarde. No entanto, a história era importante componente do ensino de Humanidades. Além disso, é uma fonte interessante para o estudo da história da educação no período colonial brasileiro uma vez que amplia e diversifica a discussão sobre o que se ensinava em termos de conteúdo nos colégios jesuíticos, campo ainda pouco investigado mesmo no interior dos grupos de estudos sobre o período.

\section{REFERÊNCIAS}

ANTONIO VIEIRA. Clavis Prophetanum In: http://www2.dlc.ua.pt/classicos/vieira.pdf, Acesso em: 02 jul. 2007.

ARNAUT DE TOLEDO, C. A. Razão de estudos e razão política: um estudo sobre a Ratio Studiorum. Acta Scientiarum. Maringá, vol. 22, n. 1, 2000, p. 181-187.

ARNAUT DE TOLEDO, C. A.; RUCKSTADTER, F. M. M.. A filosofia educacional dos jesuítas nas Cartas do padre José de Anchieta. Acta Scientiarum. Maringá, vol. 25, n. 2, 2003, p. 257-265. 
ARNAUT DE TOLEDO, C. A.; RUCKSTADTER, F. M. M.; RUCKSTADTER, V. C. M. Verbete Padroado. In: SAVIANI, D.; LOMBARDI, J. C.; NASCIMENTO, M. I. M.

(orgs.). Navegando pela História da Educação Brasileira. Cd-Rom. Campinas: Graf. FE: HISTEDBR, 2006

ASSUNÇÃO, P. Negócios Jesuíticos: o cotidiano da Administração dos Bens Divinos. São Paulo: Editora da Universidade de São Paulo, 2004.

BAETA NEVES, L. F. O combate dos soldados de Cristo na terra dos papagaios. Rio de Janeiro: Forense Universitária, 1978.

BITTAR, M.; FERREIRA JÚNIOR, A. A pesquisa em história da educação colonial. In: PAIVA, J. M.; BITTAR, M.; ASSUNÇÃO, P. (orgs.). Educação, História e Cultura no Brasil Colônia. São Paulo: Arké, 2007.

BONUCCI, A. M. Epítome Cronológico, Genealógico e Histórico. Lisboa: Oficina de António Pedroso Galrão, 1706.

BUARQUE DE HOLLANDA, S. Raizes do Brasil. São Paulo: Companhia das Letras, 2002.

CARDOSO, C. F. Um historiador fala de Teoria e Metodologia: ensaios. Bauru: Edusc, 2005.

DANIEL-ROPS (HENRI PETIOT). A Igreja da Renascença e da Reforma: II. A reforma católica. São Paulo: Quadrante, 1999.

FELIPE DE ALENCASTRO, L. A economia política dos descobrimentos. In: A descoberta do homem e do mundo. São Paulo, Companhia das Letras, 1998.

FREYRE, G. Casa-grande e Senzala. Rio de Janeiro: Livraria José Olympio, 1981.

MORAES, A. C. R. Bases da formação territorial do Brasil: o território colonial brasileiro no "longo" século XVI. São Paulo: HUCITEC, 2000.

O’NEILL, C. E. (S. I.); DOMÍNGUEZ, J. M. (S. I.) (dir.) Diccionario Histórico de la Compañia de Jesús: Biográfico-temático. 4 vol. Roma: Institutum Historicum, S. I.; Madrid: Universidad Pontifícia Comillas, 2001.

PAIVA, J. M. Colonização e Catequese. São Paulo: Arké, 2006.

SAVIANI, D. A pedagogia no Brasil: história e teoria. Campinas: Autores Associados, 2008.

SERAFIM LEITE. História da Companhia de Jesus no Brasil. 10 volumes. Belo Horizonte: Itatiaia, 2000.

\section{SÍTIOS ELETRÔNICOS}

http://books.google.com.br. Acesso em: 13 abr. 2010.

Revista HISTEDBR On-line, Campinas, número especial, p.76-85, mai.2010 - ISSN:1676-2584 84 
http://easyweb.uniba.it. Acesso em: 13 abr. 2010.

http://www.biblio.unigre.urbe.it/owsbin/owa/newbib.detailed?lang_id=1\&book_id=01615 83. Acesso em: 03 ago. 2006.

http://www.bn.br. Acesso em: 05 ago. 2006.

http://www.camara.gov.br/Internet/InfDoc/novoconteudo/acervo/catalogo/indices.pdf. Acesso em: 02 jul. 2007.

http://www.capes.gov.br. Acesso em: 03 jul. 2007.

http://www.iantt.pt. Acesso em: 24 abr. 2006.

http://www.ieb.usp.br. Acesso em: 02 jul. 2007.

http://www.morelli.it/xx_dettaglio.asp?NINVE=888. Acesso em: 03 ago. 2006.

http://www2.dlc.ua.pt/classicos/vieira.pdf. Acesso em: 02 jul. 2007.

\section{NOTAS}

\footnotetext{
${ }^{1}$ Uma versão preliminar deste texto foi apresentada no VIII Seminário Nacional de Estudos e Pesquisas do HISTEDBR (Grupo de Estudos e Pesquisas "História, Sociedade e Educação no Brasil"), realizado na UNICAMP em 2009.

2 Em pesquisa virtual pelas bibliotecas das principais Universidades Italianas e portuguesas foram encontradas referências importantes, como por exemplo, o fato de que António Maria Bonucci escreveu mais de uma vida de Santo, como a Istoria di S. Apollonia. Visualizado em http://www.biblio.unigre.urbe.it/owsbin/owa/newbib.detailed?lang_id=1\&book_id=0161583, consulta realizada dia 03/08/2006, e a Istoria di S. Trofimo arcivescovo di arles, consultado no endereço http://www.morelli.it/xx_dettaglio.asp?NINVE=888.

${ }^{3}$ O Colégio da Bahia foi oficialmente fundado em 1590-1, depois de quase vinte anos de obras. Mais detalhes do processo de estabelecimento do colégio, bem como de seu funcionamento, podem ser consultados no Tomo I da História da Companhia de Jesus no Brasil de Serafim Leite (2000).

${ }^{4}$ Exemplares deste manual podem ser encontrados na Biblioteca del Dip. di Studi Classici e Cristiani da Universitát degli Studi di Bari, bem como na Biblioteca Nazionale Centrale di Firenze, além de uma versão digitalizada disponível em: http://books.google.com.br. Acesso em: 13 abr. 2010.

${ }^{5}$ Sobre a catequese dos índios há duas importantes referências: PAIVA (2006) e BAETA NEVES (1978)

${ }^{6} \mathrm{O}$ acervo das duas bibliotecas se encontra disponível na rede mundial de computadores nos endereços: http://www.camara.gov.br/Internet/InfDoc/novoconteudo/acervo/catalogo/indices.pdf, acessado no dia 02/07/2007; e http://www.ieb.usp.br, acessado no dia 02/07/2007.

${ }^{7}$ As obras de cunho histórico escritas durante a Idade Média no interior da Igreja Católica, basicamente se apresentam divididas em três gêneros: hagiografias, anais ou crônicas e biografias e autobiografias. Resquícios desses modelos permaneceriam ainda durante a Idade Moderna. Ver mais sobre o assunto em texto intitulado Panorama da Historiografia Ocidental (até aproximadamente 1930), de autoria de Ciro Flamarion CARDOSO (2005).
}

Artigo recebido em: 01/04/2010

Aprovado para publicação em: 02/06/2010

Revista HISTEDBR On-line, Campinas, número especial, p.76-85, mai.2010 - ISSN:1676-2584 